\title{
La elección de Senadores de 1891 en Andalucía
}

\section{FRANCISCO ACOSTA SANCHEZ}

La ley Electoral de 1890 marca, con la incorporación del sufragio universal al sistema político español, uno de los hitos significativos en el proceso de desarrollo del liberalismo político en nuestro país. Las primeras elecciones generales al amparo de la nueva ley tienen lugar en Enero del año siguiente, pero solo para la Cámara de Diputados.Las elecciones para el otro Cuerpo Colegislador, el Senado, continuaron rigiendose por la Ley Electoral de Senadores de 8 de febrero de 1877.

El sistema político de la Restauración diseñado por Cánovas contenía una serie de mecanismos destinados a atemperar y a desfigurar los posibles efectos de un sufragio universal ejercido en puridad.El principal, el caciquismo, operaba a nivel socio-político restringiendo el acceso al gobierno a los partidos del turno, mediante el pacto y el fraude electoral.Junto al caciquismo, a nivel institucional el sistema preveía el control de la voluntad popular a través de la vigilancia parlamentaria de la Cámara Baja, depositaria de dicha voluntad, por parete del Senado.

El Senado del 76 se concibe en efecto como el representante de los valores permanentes de la sociedad frente al Congreso, del que debe ser eficaz contrapeso. El senador Ruiz Gómez, interpretaba el espíritu de la constitución restauradora cuando afirmaba: «Yo soy partidario del Senado, porque be observado constantemente que alli donde ba babido una sola Cámara, ba babido siempre exceso de atribuciones, porque el individuo que no tiene limitadas sus atribuciones, como la Cámara que tompoco tiene esa limitación, propende al exceso y a la exageración." $\mathrm{O}$ a quel otro senador: "El Senado representa intereses distintos de los del Congreso; el Senado representa lo que existe; el Congreso la innovación; y de las combinaciones, de las amalgamas de estos intereses el conservador y el prcgresi-

(1) Diario de Sesiones del Senado, 1876, 21 de Junio.

DOI: http://dx.doi.org/10.25267/Trocadero.1993.i5.08 
vo, resulta la armonía que debe haber para la redacción y aprobación de las leyes. ${ }^{2}$

Junto a esta idea, la naturaleza del Senado estaba animada por otra que justificaba su composición y forma de elección.La más clara expresión de lo que se entiende debe ser el Senado en lo tocante a sus miembros, la encontramos en la exposición de motivos del Gobierno a las Cortes que antecede al proyecto de ley sobre elección de senadores:

... la representación que tratándose de la Cámara popular se asienta sobre una base única y general, debe modificarse respecto del Senado, para dar entrada en él a los distintos órdenes de interés que constituyen el organismo politico y social (...)

Por eso la parte electiva del Senado (...) no ha de ser la representación vaga, indeterminada y puramente individualista de un grupo de ciudadanos, unidos cuando más por un pensamiento político o por una aspiración de partido, sino la de grandes fuerzas sociales que deben estar igualmente solicitadas por el impulso del progreso que por el espíritu de conservación.

Esta es la verdadera diferencia que hay que buscar entre ambos cuerpos colegisladores ... (...)

...si el Gobierno al proponer para el Senado una organización más bien social que politica, dando representación activa a todos los elementos de la sociedad española, se equivoca en sus cálculos; si la Iglesia, la ciencia, las artes, las letras, las armas, la industria y el comercio, al constituirse en Asamblea no se sobrepusieran a las pasiones individuales y a los intereses pasajeros de los partidos políticos para atender únicamente al bien general, babría serios motivos para desconfiar del porvenir de España. ${ }^{3}$

El deseo de dar al Senado una base representativa diferente de la del Congreso justifica la pervivencia del sufragio censitario para la Cámara Alta.La Constitución de 1876 distingue en su artículo 20, tres grandes categorías de senadores: por derecho propio y vitalicios nombrados por la Corona, en número de 180 entre ambas categorías; y elegidos por las corporaciones y mayores contribuyentes en igual número.

Vamos a ocuparnos aquí de los senadores electivos.

\section{EL CENSO ELECTORAL: ELECTORES Y NIVELES DE PARTICIPACION.}

Según la Ley Electoral de Senadores de 1877, cada provincia elegiría tres senadores -150 en total- reservándose los treinta restantes para las corporaciones del Estado en la siguiente proporción:

(2) D.S.S., 1876, Rodriguez Vaamonde, 21 de Junio.

(3) D.S.S., 1876, Apéndice $7^{\circ}$ al $n^{2} 60$. 
- 9 elegían los Arzobispados de Toledo, Sevilla, Granada, Santiago, Zaragoza, Tarragona, Valencia, Burgos y Valladolid.

- 1 cada una de las Reales Academias: Española, de la Historia, de Bellas Artes, de Ciencias Exactas, físicas y naturales, de Ciencias morales y políticas, y de Medicina de Madrid.Seis en total.

- 10 las Universidades de Madrid, Barcelona, Granada, Oviedo, Salamanca, Santiago,Sevilla, Valencia, Valladolid y Zaragoza; y

- 5 las Sociedades Económicas de Amigos del País agrupadas en las cinco sedes de Madrid, Barcelona, León, Sevilla y Valencia.

A Andalucía lé correspondió elegir 28 senadores en las elecciones de 1891.Veintitres eran elegidos por las provincias a razón de tres cada una de ellas, excepto Huelva que solo elegía dos en virtud del R.D. de 9 de Enero de 1879 por el que se establecía el derecho de las provincias ultramarinas de Cuba y Puerto Rico a elegir senadores.Para que ello fuera posible sin alterar el número total de senadores electos se dispuso que las provincias españolas con menor número de habitantes, entre las que se contaba Huelva, elegieran solo dos.Esta situación se mantuvo hasta que en $1899^{4}$ tras la pérdida de las colonias, Huelva recobró sus tres escaños iniciales.

A las Universidades de Granada y Sevilla con asistencia del Rector y Catedráticos de las mismas, Doctores matriculados en ellas, Directores de Institutos de segunda enseñanza y jefes de las Escuelas especiales que haya en su respectivo territorio, correspondía elegir dos senadores.

Dos elegían también los Arzobispos, Obispos y Cabildos eclesiásticos de cada uno de los Arzobispados de Sevilla y Granada.

Por fín las Reales Sociedades Económicas de Amigos del País de Sevilla, Almería, Baena, Baeza, Cabra, Cádiz, Córdoba, Granada, Huelva, Jaén, Jerez, Las Palmas, Málaga, Santa Cristobal de la Laguna, Montilla y Veger designaban, reunidas para el acto electoral en la sede de la de Sevilla, un senador.

En resumen, Andalucía aportaba el $15,5 \%$ del total de senadores electos del país.

El cuerpo electoral es censitario y la elección es en segundo grado excepto en las Universidades donde los electores reseñados eligen directamente al senador.En el resto de los casos, los electores designan una serie de compromisarios y estos al senador.El censo provincial para el primer grado, es decir para la elección de compromisarios, estaba compuesto por los miembros del Ayuntamiento-Alcalde y concejales- y por los máximos contribuyentes, vecinos del municipio, en número cuádru-

(4) Real Decreto de 16 de Marzo de 1899 fijando el número de senadores que ha de elegir cada provincia. 
plo a los miembros del Ayuntamiento.Cada municipio elegía un número de compromisarios igual a la sexta parte de los concejales.Los distritos donde el número de concejales no llegaba a seis tenían derecho no obstante a elegir un compromisario. Los compromisarios municipales elegidos sumados a los Diputados provinciales, reunidos en la capital de la provincia, elegían los senadores en la proporción indicada.En el cuadro siguiente se relacionan el número total de electores -compromisarios y Diputados provinciales- con que cada una de las provincias andaluzas podía participar en el segundo grado electoral y el número real de participantes en 1991:

$\begin{array}{lccccccccc} & \text { CORDOBA } & \text { ALMERIA } & \text { JAEN } & \text { MALAGA } & \text { GRANADA } & \text { SEVILLA } & \text { CADIZ } & \text { HUELVA } & \text { TOTAL } \\ \text { NN TOTAL ELECTORES } & 150 & 152 & 163 & 175 & 264 & 171 & 118 & 121 & \mathbf{1 3 1 4} \\ \text { VOTANTES } & 134 & 143 & 142 & 158 & 243 & 161 & 98 & 95 & \mathbf{1 1 7 4} \\ \% & 89,3 & 94 & \mathbf{8 7 , 1} & 90,2 & 92 & 94,1 & 83 & 78,5 & \mathbf{8 9 , 3 4}\end{array}$

La restricción del censo electoral a los mayores contribuyentes excluía a las opciones políticas no dinásticas al negar el voto a sus bases sociales naturales.Incluso quedaba escaso margen para los partidos ajenos al turno ya que la preeminencia conferida al voto rural en virtud del sistema electoral, optimizaba los mecanismos caciquiles y fagocitaba el posible dinamismo de un voto urbano que ya de por si era poco progresista si consideramos las condiciones socio-económicas de los electores.Valga como ejemplo el caso malagueño, para el que contamos con la relación completa, circunstancia ciertamente inusual en un acta electoral de senadores, de los compromisarios que participaron en la elección y de los municipios a los que representaban.De los 96 municipios que enviaron compromisarios, 73 estaban únicamente representados por uno lo que equivale a que el número de sus concejales en ningún caso superaba los 11 -recordar que se elegía un compromisario por cada 6 concejales y uno aquellos municipios que no llegaran a seis-; 20 elegián dos compromisarios, y las cuatro poblaciones más pobladas tenían derecho a elegir 18 compromisarios. ${ }^{5}$

En las circunscripciones eclesiásticas tenían derecho directo a voto en virtud de su zargo los Arzobispos y Obispos.Los cabildos por su parte elegían un compromisario que los representara en el acto de elección verificado en Sevilla y Granada.La Diócesis hispalense agrupaba a los cabildos de Badajoz, Cadiz, Canarias, Sevilla, Ceuta y Córdoba y la granadina a los de Almería, Cartagena, Guadix, Jaén, Granada y Málaga.

(5) Málaga elegía siete compromisarios, Antequera y Velez Málaga cuatro, y Ronda tres. Los datos han sido elaborados a partir del Acta Electoral de 1891 en la provincia de Málaga.Archivo del Senado, Caja n 304, Carpeta $n^{2} 7$. 
Las Sociedades Económicas a su vez elegían un compromisario por cada cincuenta socios siempre que estos tuvieran más de tres años de antigüedad como tales.La razón de esta limitación estriba en la voluntad de impedir las filiaciones coyunturales a las Sociedades por motivos exclusivamente políticos. A la pretensión, fracasada por cierto, de despolitizar el voto de las corporaciones. La indefinición de la ley respecto al concepto de "socio" planteará numerosos problemas como tendremos ocasión de comprobar más adelante.

El cuadro siguiente reproduce la información del primero para las corporaciones:

$\begin{array}{lccccc} & \begin{array}{c}\text { ARZOB. DE } \\ \text { GRANADA }\end{array} & \begin{array}{c}\text { ARZOB. DE } \\ \text { SEVILLA }\end{array} & \begin{array}{c}\text { SOCIEDADES } \\ \text { ECONOMICAS }\end{array} & \begin{array}{c}\text { UNIVER, DE } \\ \text { GRANADA }\end{array} & \begin{array}{c}\text { UNIVER. DE } \\ \text { SEVILLA }\end{array} \\ \text { Ne TOTAL ELECTORES } & 13 & 13 & & & \\ \text { VOTANTES } & 7 & 6 & 20 & 84 & 119 \\ \% & 53,8 \% & 46,1 \% & & & \end{array}$

Para las Universidades es imposiblé, con la información del Acta Electoral, determinar el número total de electores ya que dicha fuente sólo nos informa de aquellos que votaron sin especificar la totalidad de los que tenían derecho a ello. En el caso de las Sociedades Ecónomicas, no participaron en la elección las de Baeza, Cabra, Jerez, Las Palmas, San Cristobal de la Laguna, Montilla y Veger, por lo que no conocemos el número total de compromisarios que dichas sociedades enviaban ni por consiguiente el número total de electores.

A partir de las cifras de que disponemos, y con la idea de aproximarnos al censo electoral andaluz para è Senado, hemos cálculado, al alza, que este dificilmente superaría los 33.000 electores, correspondiendo unos 31.800 a los electores provinciales y el resto, 1.200 , a los corporativos. De ello se deduce una suprarepresentación relativa de las corporaciones ya que a un senador electo por cualquiera de ellas le bastaban por término medio unos 240 votos, mientras que el electo por la circunscripción provincial precisaba de aproximadamente 1400.Incluso dentro del ámbito corporativo las diferencias son notables. Baste observar que el escaño eclesiástico en el Senado "costaba" 9 votos en Sevilla, mientras que el mismo escaño en la Universidad de Sevilla precisó en 1891, 119.

Existía igualmente la posibilidad de que un mismo individuo votara varias veces por diversos conceptos. No es inusual que algunos máximos contribuyentes voten como tales y además como socios de alguna Sociedad Económica.

(6) Los datos corresponden a la segunda Acta Electoral ya que la primera elección fué anulada por el Senado. 
El censo mengua notablemente en el segundo grado, donde apenas 1600 votos, un $4,8 \%$ del total de electores con derecho a elegir compromisarios, designan a la totalidad de los senadores andaluces.Deducidos los compromisarios excluidos y los votos no emitidos, en 1991 el número real de votos en el segundo grado electoral, asciende a 1410 .

Como puede observarse a la vista de ambos cuadros, los índices de participación son muy altos en las provincias.Incluso los porcentajes pueden crecer si computamos entre los votantes, a aquellos compromisarios cuyas credenciales no fueron admitidas por las razones que veremos, ya que si bién no ejercieron su derecho, si estaban presentes en el acto y era manifiesta su voluntad de participar en él.De modo que si sumamos a los tres compromisarios excluidos en Córdoba, a los dos de Málaga y Almería, al de Jaén y a los de Sevilla el índice de participación en dichas provincias sería aún mayor.

Sólo Cádiz y Huelva tienen índices de participación inferiores al 85\%.En principio no hay datos, ni en la prensa ni en las Actas electorales que nos permitan conocer los motivos de este «desinterés. No obstante a modo de hipótesis, es posible que el hecho de que uno de los candidatos onubenses, el Vizconde de los Asilos, sea cunero y el otro, el Marqués de Nerva y Oliva, si bien es natural de la provincia ${ }^{7}$, reside y tiene intereses en Madrid, unido a la circunstancia de la menor representación de la provincia recordemos que solo elegía dos senadores mientras que el resto de las provincias andaluzas votaban tres-, no sean ajenos a la menor participación electoral.En Cadiz, parece más claro que el retraimiento de los liberales, que no presentaron candidaturas, haya podido contribuir a un menor aflujo de compromisarios al acto electoral.Puede parecer exagerada la preocupación por unos indices de abstención que oscilan alrededor unicamente de un $20 \%$, sin embargo no hay que olvidar que este se produce en el segundo grado electoral.Si el voto delegado explica los altos índices de participación característicos de las elecciones senatoriales, - verificada la elección en los municipios, el delegado adquiere el compromiso de representar los intereses del electorado, careciendo de sentido el hecho de aceptar dicha representación para no ejercer luego el voto-, el mismo argumento justifica que la no participación de un $20 \%$ de compromisarios pueda ser un dato a considerar.

Una de las cuestiones a verificar para estas elecciones senatoriales es la posible incidencia en ellas del sufragio universal, y en que medida y sentido ello se produjo.La prensa sevillana nos proporciona un apunte, que si bien no basta por si sólo para confirmar la hipótesis de que la implantacion del sufragio opero como elemento dinamizador de los

(7) Nació en Azucena (Huelva) el 14 de Enero de 1835. 
comicios senatoriales, si camina en esa dirección.xLa Andalucía* y ‘El Progreso", destacan los comicios del 91 como los de mayor participación y lucha de entre los celebrados desde $1877^{8}$.La confirmación de la posible relación causa-efecto entre ambos hechos requiere el trabajo de datos seriados de elecciones anteriores y el abundamiento en fuentes periódisticas mas allá de lo que nosotros hemos podido hacerlo aquí.

En cualquier caso el verdadero interés está en determinar los niveles de participación en el primer grado de elección verificado en los municipios. Ello nos daría los verdaderos volumenes de abstención, y lo que es mas importante proporcionaría algunas pistas, no solo sobre el grado de vinculación de las élites económicas locales al proyecto político de una Cámara Alta pensada como su espacio parlamentario natural, si no a nivel más general, sobre los hábitos electorales y la fisonomía del caciquismo entre los estratos socio-económicamente superiores. Las dificultades para un estudio de este tipo radican en la dispersión de las fuentes y en no pocas ocasiones en la inexistencia misma de estas.

En las corporaciones eclesiásticas, únicas en las que es posible establecer la relación, al no tener datos para el resto, entre total de electores y votantes, los índices de participación son los menores, no solo a nivel regional sino en el ámbito nacional y durante todo el periodo de la Restauración.Ello se debe al sistemático retraimiento de los Obispos, que suponían el $40 \%$ del censo electoral y eran electores directos en virtud de su cargo.También eran electores directos los Arzobispos para los que la obligación de presidir el acto electoral explica sin duda su voto.Esta situación se verifica perfectamente en el Arzobispado de Granada donde en 1891 votaron todos los cabildos y el Arzobispo y ningún Obispo.En Sevilla, por contra, solo los cabildos de Cádiz, Tenerife y Ceuta eligieron sus compromisarios mientras que, contrariamente a la tendencia que acabamos de señalar, los Obispos de Cádiz y Sevilla ejercieron su derecho al voto.El otro voto, que completa los seis, fué el del Arzobispo.

\section{LAS ELECCIONES: CANDIDATOS, SENADORES E INCIDENCIAS}

El Domingo 15 de Febrero de 1891, siempre con posterioridad a las de Diputados, se celebran en todo el país las elecciones definitivas para el Senado.

En el apéndice adjunto se relacionan el reparto de votos en cada una de las provincias, la filiación política de los senadores elegidos y el

(8) -La Andalucía.Política económica y literaria.., Domingo 15 de Febrero de 1991; •EL Progreso.Diario Liberal., Miércoles 18 de Febrero de 1991. 
lugar y fecha de nacimiento de los mismos ${ }^{9}$ al objeto de poder determinar los índices de cunerismo.

Los senadores electos y vitalicios debían acomodarse a alguno de los doce tipos especificados en el artículo 22 de la Constitución. En la elección que nos ocupa, 15 de los 28 , senadores electos lo fueron en virtud del párafo 11 del art. 22:»los que con dos años de antelación posean una renta anual de 20.000 pesetas o paguen 4.000 por contribuciones directas al Tesoro público, siempre que además sean Títulos del Reino, hayan sido Diputados a Cortes, diputados provinciales o alcaldes en capital de provincia o en pueblos de más de veinte mil almas..; 7 cumplieron los requisitos del párrafo 2: "Diputados que hayan pertenecido a tres Congresos diferentes o que hayan ejercido la diputación durante ocho legislaturas.»; y de los cinco restantes, dos satisfacían los requisitos del párrafo 10: ‘Académicos de número de las corporaciones mencionadas, que ocupen la primera mitad de la escala de antigüedad en su Cuerpo; inspectores generales de primera clase de los cuerpos de ingenieros de caminos, minas y montes; catedráticos de término de las Universidades, siempre que lleven cuatro años de antigüedad en su categoría y de ejercicio dentro de ella.; los dós representantes eclesiásticos, como obispos, se hallan recogidos en el cuarto párrafo del art. 22; y el último en su calidad de ex-ministro de la Corona se adecua al parrafo $3 .{ }^{10}$

Los comprendidos en las categorías $2^{\mathbf{a}}, 3^{\mathbf{z}}, 4^{\mathrm{a}}$ y $10^{\mathbf{z}}$ debían además acreditar una renta de 7.500 pesetas como mínimo para poder ser senadores.

A pesar de que los comicios senatoriales han sido caracterizados por la acentuación de los mecanismos del pacto y consecuentemente una menor lucha electoral, ello no siempre es así.De hecho no son inusuales la confrontación electoral y los incidentes, si bien es cierto que en menor proporción respecto a los comicios al Congreso. Las elecciones de 1891 son un buen ejemplo de ello.

(9) Los expedientes de senadores, fuente principal de esta comunicación, no siempre proporcionan los datos de la procedencia y nacimiento del senador por lo que ha sido necesario recurrir a otras fuentes biográficas.Mención especial merece en este sentido la información aportada por los trabajos inéditos del Archivo del Senado.

(10) Parrafo $2^{\circ}$, art.22:Pérez García, Escavias de Carvajal, Díaz Almagro, Conde de la Infantas, Mques. de Nerva y Oliva,y de Casa Laiglesia, y Ruiz Martínez.

30: Conde de Xiquena.

4: Calvo y Valero, y Spinola y Maestre.

10: Riaño y Montero, Laraña y Fernández.

11: Mques. de la Paniega, de Casa-Pavón, de Campo de Aras, del Dilar, y de Iznate, Gozález Canet, Espinosa Bustos, Conde de los Andes, de San Bernardo, y de Bagaes, Madrid y Ruiz, Bonilla y Forcada, Vizconde de los Asilos, Lomas Martín, Moreno Mazón, y Villalón y Torres. 
Hubo lucha electoral en Almería, Granada, Jaén, Málaga y Sevilla. En Córdoba, a pesar de que los votos se repartieron entre nueve individuos, los cinco que obtienen un solo voto no pueden considerarse como representantes de opciones políticas organizadas con voluntad de oponerse al encasillado.De hecho ni tan siquiera eran candidatos.Lo mismo ocurre en Granada.La prueba la tenemos en el voto obtenido por Sagasta, absolutamente ajeno a la elección granadina.En Cádiz, por el ya mencionado retraimiento de los liberales, y en Huelva, el encasillado triunfó sin oposición.

Si la hubo en Jaén donde el fusionismo disputó con éxito, aunque por ajustado margen, las senadurías a la opción ministerial representada por conservadores y reformistas. No hubo pacto alguno.La lucha fué abierta y los dos candidatos fusionistas consiguieron encabezar la representación de la provincia en el Senado a pesar de que el Conde de Xiquena era un candidato cunero.

En Granada el conservadurismo cosecharía otro fracaso relativo pues el candidato adicto Agrela y Moreno, en contra de las previsiones de la prensa y con gran sorpresa por parte de sus amigos ${ }^{11}$, perdió su escaño en beneficio del fusionista Conde de las Infantas, lo que dejó reducida la candidatura ministerial, tras la retirada de su tercer candidato Ricardo Chacón, al Marqués del Dilar.El escaño de Díaz Almagro, apoyado por liberales y posibilistas, era considerado seguro antes de la elección.

Mejor suerte tuvo el encasillado en Málaga donde la prensa destaca la coalición entre conservadores y romeristas (reformistas) contra el fusionismo en revancha de la derrota sufrida en las elecciones a diputados.El resultado es que se han puesto en juego todos los resortes del gobierno contra el único candidato de oposición el fusionista Juan Peralta Aperteguía- que goza aquí de generales simpatíasw. ${ }^{12}$

En Sevilla el gobierno encasilló al candidato romerista De la Cuadra y Gibaja sin embargo este quedó excluido del reparto de credenciales en beneficio del fusionista Ruiz Martínez. Asistimos aquí a un caso de ruptura del pacto debido a la no aceptación de las directrices ministeriales centrales por parte del elemento local, capaz de resistir la presión de su propio partido, el conservador, que había pactado la senaduria de De la Cuadra con el sector romerista. Ya .El Tribuno* adelantaba antes de las elecciones que a pesar de la obligación de los conservadores de votar al candidato reformista, muchos no acatarían la consigna.Las responsabilidades del fracaso del pacto recayeron sobre el Gobernador Civil, El Sr.Aranda que pagó con su cargo la indisciplina del electorado conservador sevillano.

(11) El Imparcial 16 de Febrero de 1891.

(12) Idem. 
También entre las incidencias hay que mencionar el documento remitido directamente a la Comisión de Actas del Senado por, el diputado provincial Diego Rodríguez Sánchez, donde denuncia, apoyándose en una información del Diario fusionista "El Progreso" de Sevilla, que el Sr. Villalón ha falseado los documentos que acreditan su renta al no haber pagado en los últimos dos años las 4.500 pesetas de contribución que exige la ley (párrafo 11 del art. 22) para ser senador.La denuncia no fué tomada en consideración por la Comisión de Actas, y si lo fué no provocó desde luego Dictamen alguno contra la aptitud legal del acusado.Según el periódico mencionado, la senaduría del Sr. Villalón era la recompensa a este, jefe del conservadurismo en Morón, por sus votos al candidato cunero encasilla do en aquel distrito para el Congreso.Este episodio viene a apoyar la idea de la conexión entre los comicios al Congreso y la definición de las candidaturas senatoriales.Idea manifiesta igualmente en el hecho de que el pretendido escaño del jefe del reformismo sevillano, De la Cuadra, había sido prometido a cambio de la retirada de su candidatura por Utrera en las elecciones al Congreso. ${ }^{13}$

En Almería igualmente el gobierno cede un escaño a las oposiciones.En este caso la lucha se produce entre fusionistas y martistas.

Ya las elecciones para la Mesa electoral suscitaban el interés de la prensa pues del resultado podía deducirse el verdadero estado de las fuerzas contendientes y el subsiguiente desenlace.Así pues "El Imparcial* y :La Epoca*, el mismo día 15 adelantan los resultados sobre la composición de las diferentes Mesas que como se puede comprobar se aproxima casi perfectamente al resultado final: en Almería componían la Mesa electoral 3 secretarios adictos y 1 fusionista,- el Presidente no se elegía.En Cádiz, Huelva y Córdoba 4 adictos; adictos y reformistas se repartían por igual en Málaga las cuatro secretarías; en Granada 109 votos para la Mesa fueron conservadores y 92 liberales, mientras que en Sevilla la proporción fué de 103 frente a 49.

En las corporaciones el índice de lucha electoral es, por lo general, todavía menor.Muy esporadicamente ocurre, como en el Arzobispado de Sevilla, que más de un individuo obtenga votos.Aunque carecemos de datos para determinar si hubo en realidad dos candidatos y por lo tanto lucha electoral, lo cierto es que el acta sevillana rompe con la constante de la unanimidad del voto, característica en las circunscripciones eclesiásticas.En la Universidad de Sevilla, el voto obtenido por Campos y Oviedo no es políticamente significativo, encontrandonos una vez más ante ese voto que podríamos calificar de testimonial o marginal, fuera del

(13) El Tribuno.Diario Político de la tarde.x, Martes 17 de Febrero de 1991. 
contexto político y de la relación de fuerzas contendientes en una coyuntura electoral determinada.

Donde si hubo lucha electoral fué en la elección de las Sociedades Económicas de Amigos del País de Andalucía y Canarias.Ello se explica en buena medida si consideramos que las Sociedades Económicas, lejos del espíritu e intenciones de la ley de dotar de independencia a las corporaciones apartándolas del radio de acción de los intereses partidistas, fueron en realidad auténticas cajas de resonancia del ambiente político del momento y fieles traductoras de las tensiones y equilibrios imperantes entre los grupos of facciones contendientes. Una simple muestra de ello es la participación directa de las familias políticas en el acto electoral.Así D.Pedro Rodríguez de la Borbolla miembro del poderoso clan liberal sevillano, era nada menos que el único delegado de los seis compromisarios gaditanos ${ }^{14}$.Por Granada, los compromisarios no son otros que el Conde de las Infantas y Valentín Agrela y Moreno, candidatos a la senaduría por la provincia.

Reunidos el 15 de Febrero en Sevilla todos los compromisarios de las sociedades económicas andaluzas y canarias ${ }^{15}$, excepto los de Baeza, Cabra, Las Palmas, Montilla y Veger que no asistieron, la elección se va a polarizar en torno a dos grupos encabezados por D. Luis Huertas y Arranz, compromisario por la S.E. sevillana, y D. Pedro Rodríguez de la Borbolla.La elección de compromisarios venía marcada por una serie de irregularidades denunciadas por el Sr. Huertas que defendió la no aceptación de los compromisarios elegidos por la S.E. de Almería por no haber cumplido los plazos marcados por la ley para la elección de compromisarios, lo mismo le sucedía a la de Huelva y a la de Cádiz.Esta última además había incluido entre sus socios a los corresponsales, cuando una Real Orden había aclarado, ante la confusión suscitada con anterioridad en este sentido, que solo los socios residentes formaban el censo electoral para la elección de compromisarios. Dicha irregularidad se ve confirmada por $\cdot$ El Manifiesto ${ }^{16}$ que denuncia la estratagema de D. Cayetano del Toro, cacique fusionista, de incluir en la lista de la S.E.gaditana, a los socios corresposales de Cuba y Buenos Aires con el fin de que resultara elegido el candidato fusionista.El resultado de la inclusión de los socios

(14) La ley permitía a los compromisarios elegidos por las Sociedades Económicas delegar su voto.Ello facilitaba sin duda la -politización. de la elección y permitiá la la actuación del sistema de relaciones caciquiles.

(15) 2 por la S.E. de Almería, 2 por las de Baena, Málaga; San Cristobal de La Laguna y Granada (uno de los de Granada no asistió al acto), 6 por la de Cádiz, 19 por la de Córdoba, 1 por la de Huelva, 5 por la de Jaén, y 3 por la de Sevilla.En total 44
compromisarios.

-(16) Diario Republicano-Progresista de Cádiz., 16 de Febrero de 1891. 
corresponsales es la elección de mayor número de corresponsales de los que en realidad le son propios ${ }^{17}$. Tambíen pidió el Sr. Huertas la anulación de las actas de los compromisarios de San Cristobal de la Laguna por no hallarse completa su documentación.

El acta electoral de la Económica de Córdoba fue sin duda la más polémica puesto que en el momento de la elección dicha sociedad estaba suspendida por el Gobernador Civil de Córdoba.Este es uno de los argumentos esgrimidos por el $\mathrm{Sr}$. Huertas para pedir la anulación del acta cordobesa.El otro fué, una vez más, la inclusión de socios corresponsales en las listas del censo en número tal que los cordobeses se presentaban en Sevilla con 19 compromisarios.La conducta del gobernador fué reprobada por el delegado de los 19 compromisarios cordobeses, por uno de los compromisarios de Jaén que calificó la suspensión de coacción y abuso de autoridad por ser en época de elecciones, y por el Sr. Rodríguez. de la Borbolla.Este se opuso en todo momento a las consideraciones del Sr. Huertas, argumentando que la Junta Electoral y la Mesa solo tenían competencia para elegir el senador que la ley les asignaba, pero no para determinar la validez de las elecciones de las diferentes sociedades, potestad que correspondía en exclusiva al Senado.

La Mesa resolvió finalmente aceptar a todos los compromisarios excepto a los de Córdoba por la suspensión gubernativa que pesaba sobre ellos.A pesar de la protesta de dos compromisarios de Jaén y del $\mathrm{Sr}$ Rodríguez de la Borbolla que calificaron de arbitrariedad y atentado la discriminación de los compromisarios cordobeses, participaron en la elección solamente 24 compromisarios (ver nota 13 ).

De haber sido admitidos los compromisarios cordobeses hubiera resultado elegido, hecho sin precedentes, un candidato republicano, José Moreno Rodríguez, ya que la delegación cordobesa expresó por escrito en el acta su voluntad de votar por dicho candidato. Esta es la cuestión de fondo que impulsó al gobierno a activar, por vía del Gobernador Civil de Córdoba, la suspensión de la sociedad cordobesa. Así por lo menos lo entendió parte de la prensa ${ }^{18}$,y de al Cámara Alta. El senador liberal Pacheco denunció en el Senado durante la discusión del acta electoral que nos ocupa, que la verdadera intención del gobierno era impedir el acta senatorial para el candidato republicano ${ }^{19}$. La Comisión de Actas y Calidades de la Cámara Alta propuso la anulación de la elección por las manifiestas

(17) Recordar que a cada Sociedad Económica correspondía un compromisario por cada cincuenta socios.

(18) .El Cronista. de Sevilla, 18 de Febrero de 1891, .El Manifiesto. de Cádiz, 16 de Febrero de 1891.

(19) Diario de Sesiones del Senado, 1891, p. 862. 
irregularidades, tanto en la elección de compromisarios como en la de senadores, y reprobó en su dictamen la actitud del Gobernador Civil de Córdoba. Tras la discusión del Dictamen de la Comisión, en la que algunos senadores como el antedicho, propusieron que los votos de la Sociedad Económica cordobesa debían ser computados y proclamado senador el candidato republicano, la elección fue definitivamente anulada.

El 12 de Julio las Sociedades Económicas andaluzas y canarias se reunían de nuevo para elegir senador.En esta ocasión como ya hemos señalado la participación fué menor ${ }^{20}$. También en esta convocatoria hubo protestas.Destacaremos en este sentido la acusación del compromisario cordobés Jiménez Amigo al gobierno por la forma de convocar las eleciones.Forma que, según él, había impedido a algunas sociedades elegir sus compromisarios por lo escaso de los plazos señalados para ello.También se apreció la reincidencia en algunos de las infracciones que motivaron la suspensión del acta anterior.A saber la verificación de actos electorales fuera de los plazos legales establecidos o la elección de algún compromisario mas de los correspondientes según el número de socios.En esta ocasión sin embargo la Comisión de Actas del Senado no tuvo inconveniente en proponer la aprobación del acta, arguyendo con toda probabilidad, - no nos consta para este caso pero es lo habitual en otros similares- que la corrección de las irregularidades no variaría el resultado del escrutinio.

También se oyeron en el Senado voces contrarias a las condiciones generales en que se habían desarrollado aquellas elecciones de 1891.El 7 de Marzo la Minoria Constitucional, a través del Sr. Romero Girón denuncia ante la Cámara irregularidades como la ausencia de información, en los expedientes remitidos por las provincias, sobre listas de compromisarios y constitución de la Mesa para la elección.Denuncia igualmente la arbitrariedad en la elaboración de los censos electorales, debida en buena medida a la confusa reglamentación del gobierno al respecto ${ }^{21}$ y a la voluntad de manipular las elecciones.Para ello, dice Rodríguez Girón, se dedicó el gobierno a -moralizar. la administración municipal en momentos próximos a las elecciones y acontecieron entonces las suspensiones y procesamientos de multitud de Ayuntamientos y la constitución de interinos que vieron reconocido su derecho al voto y su capacidad para organizar las elecciones. El resultado, concluye, es que las elecciones a senadores se han verificado por dos censos diferentes: el del año ante-

(20) Las' Sociedades de Almería, Baena, Cadiz, Córdoba, Granada y Málaga, eligieron 2 compromisarios respectivamente; 1 eligieron las de Huelva y Sta. Cruz de Tenerife; y 3
las de Sevilla y Jaén. 20 en total.

(21) La Ley Electoral de senadores disponía que los censos debían estar ultimados antes del día 8 de Marzo.Al tener las elecciones de 1891 fecha anterior a dicho plazo, el gobierno por Real Orden de 25 de Enero de 1891 estableció criterios transitorios para su elaboración. 
rior, 1890, en aquellos municipios donde no estaba ultimado el actual, y el censo elaborado por los Ayuntamientos interinos.

En las provincias las protestas e incidencias, cuando se dieron, fueron de menor magnitud.La circunstancia más usual en estas elecciones, es la reclamación por la no aprobación de algún acta de compromisario.Esto ocurrió en Almería con los dos compromisarios de Zatral y Bayareal cuya credencial no fué admitida al no haberse recibido el acta de elección de sus respectivos Ayuntamientos.La misma razón impidió votar a los compromisarios de los municipios cordobeses de Aguilar, Villanueva y Villaviciosa y a los dos del municipio malagueño de Casares.En principio no hay razones para creer, por los resultados de la elección y el número de votos obtenido por los diferentes candidatos, que dichas exclusiones encubran, en estos casos, motivos políticos.Menos claro es el caso del compromisario de Jaén, donde si hubo lucha electoral ajustada, al que se impidió el voto por no estar adecuadamente verificada su credencial, cuando el día anterior se le había permitido votar para la elección de la Mesa.En Málaga según denuncia la prensa los candidatos se habían visto obligados a votar con papeleta abierta lo que si es un método frecuente de coacción en las elecciones senatoriales.Igualmente lo es la areunión. del Gobernador Civil con los compromisarios antes del momento de la elección.Si bien esta práctica no está verificada para Andalucia en estas elecciones, El Liberal. ${ }^{22}$ lamenta la frecuencia de dichas reuniones en todo el país.Aún así no faltó quién propuso al final del acto en Málaga agradecer a la Mesa su imparcialidad y rectitud.Los mismos reconocimientos se repiten en el acta de la Universidad de Granada, donde destaca optimista el corresponsal de El Imparcial ${ }^{23}$ :Se ha hecho con perfecta legalidad la votación de senadores (...).Se cree que el resultado de la votación (...) por la provincia influirá mucho, modificando la marcha de la política en Granada."

En Sevilla, la prensa se hizo eco de las anormalidades de la elección de compromisarios en varios municipios.En Marchena, según "El Progreso, viendo perdida los conservadores la elección *armaron un tiberio de padre y muy señor mio ${ }^{24}$.Ello permitió al gobernador civil, al que acusan de indulgente y complice con los alborotadores, a suspender el acto hasta el día siguiente, a pesar de que la competencia de la suspensión fuera exclusiva de la Junta electoral provincial. En Aguadulce, dos horas antes de la elección, el Alcalde conservador y sus correligionarios, designaron a los compromisarios negando a los electores su derecho al voto.Se denuncia

(22) 17 de Febrero de 1991.

(23) 16 de Febrero de 1991.

(24) .El Progreso, Martes 10 de Febrero. 
igualmente la monterillada ${ }^{25}$ ejercida en Cazalla de la Sierra donde habiendo ganado los liberales la elección, el Alcalde proclamó un candidato conservador y otro liberal. La Junta electoral provincial no admitió ninguna de las actas de los compromisarios de estas tres localidades.

El cunerismo, como se puede comprobar por los lugares de nacimiento de los senadores, esta moderadamente presente en estas elecciones en Andalucia.Incluso en aquellos casos para los que carecemos de datos de nacimiento completos, como ocurre con el Conde de los Andes o Lomas Martín, conocemos algunas circunstancias que nos permiten vincularlos a la provincia por la que son elegidos.Así sabemos que el Conde de los Andes era vecino de Jérez de la Frontera, que poseía un notable volumen de propiedades en dicha localidad y que fue senador en tres ocasiones siempre por Cádiz; Lomás Martín a su vez, había sido con anterioridad diputado provincial, y a Cortes por la provincia de Málaga y volverá a ser senador por la misma.Además acreditó sus rentas con bienes rústicos en Málaga, por lo que lo más probable es que ninguno de los dos sea cunero.El caso de Espinosa Bustos es diferente puesto que su expediente está incompleto y disponemos de escasos datos complemetarios a fin de determinar su posible procedencia.El senador por Córdoba Esçavias de Carvajal y Sandoval aparece más vinculado a la provincia de Granada, en la que nos consta es propietario y por uno de cuyos distritos fué diputado, aunque también fué senador por Castellón en 1896.

Considerando estos datos, el 18\% de los senadores andaluces han nacido fuera de la región ${ }^{26}$, y entre el resto solo dos fueron senadores por provincias que no eran las suyas, lo que elevaría el porcentaje de cuneros al $27 \%$.

Incluso los senadores electos por las corporaciones, para los que, a nuestro juicio, sería discutible la calificación de cuneros, ya que el objeto de su representación no es una provincia si no una corporación, son en este caso todos andaluces.

En cuanto a la filiación ideológica, Andalucia aportó al Senado de 1891, 15 conservadores, 7 fusionistas, 3 romeristas o reformistas, y 1 posibilista.Traducido en porcentajes respecto al total nacional ello representaba, el $12 \%$ de los consevadores, el $18 \%$ de los fusionistas, el $42 \%$ de los reformistas, y la totalidad de los posibilistas.

No quisieramos concluir sin intentar una caracterización sociológica, aunque sea esquemática, de los senadores andaluces.La edad media del senador andaluz es de 52 años, siendo el más joven Pérez Garcia con $37^{27}$, y el más anciano Laraña y Fernández con 75 .

(25) Id.Sábado 14 de Febrero

(26) No se ha considereaado a Espinosa Bustos y se han incluido al Conde de los Andes, a Lomas Martín y a Escavias de Carvajal entre los andaluces. 
Socioprofesionalmente ${ }^{28}$, y atendiendo a la tipología ya clásica para la clase política de la Restauración, podemos distinguir dos grupos: el de los profesionales liberales y el de los propietarios. En el primero incluimos a dos diplomáticos, el Conde de Xiquena y el Marqués de Casa Laiglesia, dos catedráticos, de Derecho Civil, el senador elegido por la Universidad de Sevilla, y de Lengua Arabe y Diplomática, el electo por la de Granada.Un periodista si por tal podemos entender al Vizconde de los Asilos, propietario del periódico "La Correspondencia de España*.También sería posible catalogarlo como industrial.Y dos abogados, Espinosa Bustos y Díaz Almagro, que nos consta ejercían su profesión, ya que hay entre los senadores andaluces, otros como Spinola y Maestre, Laraña y Fernández, el Marqués de Casa-Pavón o el Marqués de Dilar, que si bién tienen una formación jurídica no ejercieron como abogados.La formación jurídica es sin duda otra de las constantes entre la clase política de la Restauración.

Una característica de este grupo es que por lo general la mayoría se vinculan en mayor o menor medida, en algún momento, a la Administración del Estado a través de diferentes cargos políticos.En esta situación estan Laraña y Fernández que es nombrado Rector de la Universidad de Sevilla en 1876, Riaño y Montero, Consejero de Estado en dos ocasiones (1883 y 1893) y Ministro del Tribunal de lo Contencioso-administrativo en 1894; Diaz Almagro, Secretario del gobierno civil de Granada durante la República y Subsecretario de Estado más tarde.

De expediente más dilatado son los dos diplomáticos.El Conde de Xiquena cuenta entre sus cargos una Vicepresidencia del Congreso en 1863, y una subsecretaría de Estado en 1868.Fué ademas gobernador de Madrid y Ministro de Gracia y Justicia, de Ultramar y de Fomento en dos ocasiones.El Marqués de Casa Laiglesia, si bien solo nos consta fué Gobernador Civil de Cádiz, cuenta con una hoja de servicios como diplomático mucho mas extensa con representaciones en catorce ciudades diferentes. En lo que se refiere a Espinosa Bustos y al Vizconde de los Asilos desconocemos si desempeñaron cargos políticos.

Los propietarios conforman un grupo amplio en el que, a menudo, la combinación de diferentes actividades económicas hace resbaladizo e impreciso el límite del mismo.En cualquier caso todos los que hemos incluido en este grupo son catalogado como tales en las fuentes consultadas, aunque es habitual que combinen su labor como propietarios agrícolas con otras actividades en diferentes ámbitos sin que quede clara la proporción en cuanto al nivel de importancia entre las diversas

(27) La edad mínima para ser senador, especificada en la Constitución, era de 35 años.

(28) Carecemos de información en este sentido para Pérez García, Conde de San Bernardo, de las Infantas, de Nerva y Oliva y de Iznate y Marqués de Campo de Aras. 
ocupaciones.Así, por ejemplo, González Canet es banquero, el Marqués de Casa Pavón contribuye por ganadero y por industrial en el concepto de criador de vinos, y el Marqués de Dilar es, aparte de gran propietario y ganadero, propietario de una fábrica de hilados en Dilar (Granada).El resto, Lomas Martín, El Marqués de la Paniega, Conde de los Andes, Escavias de Carvajal, Ruiz Martínez, Villalón y Torres, y Madrid y Ruiz, no nos consta tuvieran otra ocupación mas que la de propietario.

El caso de Moreno Mazón es el único en el que nos encontramos con un industrial y comerciante que no es propietario agrícola.Director de la Sociedad -Moreno Mazón e Hijos", se dedica a la fabricación de vinos y al comercio altomarítimo en general.También consta en la matrícula de industrial como fabricante de harinas que "muele trigos, cierne y clasifica las harinas". ${ }^{29}$

Este grupo se caracteriza, en contraposición al anterior, por la tendencia a proyectarse en las esferas locales y provinciales de la vida pública.En efecto de los 12 miembros que lo componen, el Marqués del Dilar, Madrid y Ruiz, Lomas Martín y Villalón y Torres fueron diputados provinciales en su provincia; el mismo Marqués del Dilar, Moreno Mazón, el Marqués de la Paniega y González Canet fueron en una o varias ocasiones, alcaldes de su ciudad durante cortos espacios de tiempo.

Por fin, en relación a la idea, generalizada a partir de la obra de Tusell Oligarquía y caciquismo en Andalucia, de la senaduría como etapa final de la carrera política, cabría hacer diversas consideraciones.Sin incluir a los dos obispos, entre el resto de senadores, 26 , se pueden diferenciar varios grupos. Tenemos por un lado uno cuyos miembros - Marqués de Casa Pavón y Conde de los Andes- solo cuentan entre sus cargos políticos la senaduría, por lo que no puede entenderse que esta sea la etapa final de su carrera.Tampoco es exacto, a nuestro juicio, considerar las cinco senadurias del Marqués del Dilar como una última etapa de su actividad política, máxime cuando antes solo había sido alcalde de Granada durante un año, y Diputado provincial durante dos. Mas que como etapa final, en su caso, debe considerarse la senaduria como el cargo político preferente.Igual ocurre con el Vizconde de los Asilos, diputado en 1888 y senador con posterioridad en cinco ocasiones, la primera, 1891, con 38 años.

Hay otro grupo en el que la senaduría, lejos de ser la fase final de su actividad política es una experiencia transitoria y esporádica. Esto es lo que ocurre con el Conde de las Infantas, diputado en 1881 y 1883 , senador una sola vez en 1891, y de nuevo diputado en 1893 y 1898.En el mismo caso se hallan el Conde de Xiquena, senador en 1879 y $1891, y$ Diputado en 1893,1896 y 1898 -con anterioridad a 1879 lo había sido en

(29) Expediente del senador Miguel Moreno Mazón.Archivo del Senado, Caja 304, Expedien-
te $n^{2} 7$. 
seis ocasiones-; y Bonilla y Forcada, diputado en un Congreso antes de ser senador, una sola vez en 1891, para ser elegido despues en tres Congresos.Similar es el caso de Francisco Ruiz Martínez, cuatro veces diputado entre 1878 y 1886 y siete senador entre 1888 y 1901.La diferencia es que este fué honrado con la senaduría vitalicia en 1905 siendo obviamente este cargo el postrero de los que desempeño.

En el resto de los casos la senaduría es en efecto el último de los cargos políticos desempeñados si bien es cierto que caben matices. Así, por ejemplo, el Conde de Bagaes fué una vez diputado en 1879 y otra senador en 1891.Similar circunstancia es la de Villalón y Torres, diputado provincial por Morón de la Frontera (Sevilla) durante una legislatura y senador una sola vez en 1891.Espinosa Bustos y el Marqués de Campo de Aras tienen igualmente carreras políticas tan escuetas, una diputación y una senaduría cada uno- que el hecho de que la senaduria sea el último cargo, no puede considerarse que arrope adecuadamente el juicio de la senaduría como fase terminal de la carrera política.

\section{APENDICE}

ARZOBISPADO DE GRANADA.

Spinola y Maestre, Marcelo. Obispo de Málaga: 7.Independiente.

- San Fernando, (Cádiz) 1835.

ARZOBISPAD $\odot$ DE SEVILLA.

Calvo y Valero, Vicente.Obispo de Cádiz: 5.Independiente.

- Sevilla, 1838.

Sebastián Herrero, Obispo de Córdoba: 1.

UNIVERSIDAD DE GRANADA.

Riaño y Montero, Juan Facundo: 84.Conservador.

- Granada, 24 de Noviembre 1828.

UNIVERSIDAD DE SEVILLA.

Laraña y Fernández, Manuel: 118.Conservador.

- Sevilla, 24 de Febrero de 1815.

Campos y Oviedo, Manuel: 1.

SOCIEDAD ECONOMICA DE SEVILLA.

Primera elección 15 de Febrero de 1891:

Número de votantes: 24 .

Paniega, Marqués de la.José Freuller y Alcalá Galiano: 16. Conservador.

- Málaga, 21 de Marzo de 1815.

Moreno Rodríguez, José: 8 .Republicano posibilista. 
Segunda elección 12 de Julio de 1891 :

Paniega, Marqués de la.josé Freullery Alcalá Galiano: 15. Conservador.

Juán de la Rada y Delgado: 3.

José Fernando González: 1.

Moreno Rodríguez, José: 1.Republicano posibilista.

ALMERIA.

Gonzalez Canet, José. 143.Conservador.

- Almería, 27 de Febrero de 1842.

Espinosa Bustos, José. 114.Conservador.

Pérez Garcia, Sebastian: 98. Fusionista.

- Gerjal, (Almería) 1854.

Tamayo Conejero, Juan: 74. Martista.

CADIZ.

Casa Laiglesia, Marqués de.Manuel Rances y villanueva: 98. Conservador.

- Cádiz, 1824.

Andes, Conde de los.Pedro Moreno de la Serna: 98.Conservador.

- 28 de Marzo de 1830.

Casa Pavón, Marqués de.Francisco Javier López de Carrizosa y Giles: 98. Conservador.

- Jerez de la Frontera,(Cádiz) 29 de Febrero de 1836.

CORDOBA.

San Bernardo, Conde de.Manuel Mariategui y Vinyals: 126. Fusionista.

-Madrid, 23 de Mayo de 1852.

Campo de Aras, Marqués de.José Chacón y Valdecañas: 126. Conservador.

- Lucena (Córdoba) 3 de Junio de 1849.

Escavias de Carvajal y Sandoval, Fernando: 126.Conservador.

Luis LLavería: 1.

Ramón Torres Hita: 1.

Juan Bautista Pérez: 1.

Francisco Solano Rioboó: 1.

Luis Antunez: 1.

Rafael Torres de la Barrera: 1.

1 Blanco.

GRANADA.

Diaz Almagro, Melchor: 208.Posibilista.

- Granada, 13 de Marzo de 1850.

Dilar, Marqués de.Pablo Díaz Jiménez: 201.Conservador.

- Granada, 30 de Marzo de 1832.

Infantas, Conde de las.Fernando Pérez del Pulgar. 144. Fusionista.

- Granada, 15 de Febrero de 1838. 
Agrela y Moreno, Valentín: 121.

Práxedes Mateo Sagasta: 1.

Ricardo Chacón: 1.

Diego Vázquez: 1.

JAEN.

Madrid y Ruiz, Eugenio: 74.Fusionista.

- Santisteban del Puerto, (Jaén) 17 de Noviembre de 1834.

Xiquena, Conde de.José Alvarez de Toledo y Acuña: 73. Fusionista.

- París, 1838.

Bonilla y Forcada, José: 78.Liberal reformista.

- Jaén, 20 de Julio de 1838.

José de Coello y Quesada: 71. Conservador.

Marqués de Villalba: 66. Conservador.

Marqués Viudo de la Merced: 62. Conservador.

HUELVA.

Nerva y de Oliva, Marqués de.Manuel Martín de Nerva y Oliva: 95.Liberal reformista.

- Azucena, (Huelva) 14 de Enero de 1831.

Asilos, Vizconde de los.Eduardo Santa Ana y Rodriguez: 95. Fusionista.

- Madrid, 5 de Febrero de 1835.

MALAGA.

Iznate, Marqués de.Antonio Campos Garin: 127. Conservador.

- Málaga, 14 de Septiembre de 1842.

Lomas Martin, Felix: 127.Liberal reformista.

Moreno Mazón, Miguel: 131.Conservador.

- Málaga 14 de Junio de 1823.

Juan Peralta Aperteguía: 43. Liberal.

SEVILLA.

Bagaes, Conde de.Bernardo Losada y Pastor. 152.Conservador.

- La Habana, (Cuba) 28 de Julio de 1838.

Villalón y Torres, Ignacio: 147.Conservador.

- Morón de la Frontera, (Sevilla) 24 de Mayo de 1846.

Ruiz Martinez Dominguez y Gutiérrez, Francisco: 90.Fusionista.

- Cortes de la Frontera, (Málaga) 26 de Noviembre de 1841.

Enrique de la Cuadra y Gibaja: 58.Liberal reformista.

Juan Bautista del Pozo: 2.

Juan Galindo y Salado: 1. 